\title{
UMA NOVA TRADUÇÃO PARA OVÍDIO, AMORES 1.8
}

\author{
A NEW TRANSLATION OF OVID'S AMORES 1.8
}

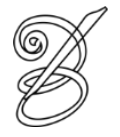 \\ Luiza dos Santos SOUZA* \\ University of Cincinnati \\ Cincinnati, Ohio, Estados Unidos da América
}

\begin{abstract}
Resumo: A presente tradução é parte uma primeira revisão do trabalho tradutório apresentado em dissertação de mestrado (SOUZA, 2016). A proposta foi traduzir os dísticos elegíacos de Ovídio em uma forma que ecoasse o ritmo original do poema latino. Para isso, partiu-se da proposta de Carlos Alberto Nunes, a substituição de longas em posição princeps por tônicas. Porém, nesta tradução, ao contrário da de Nunes, permitiu-se também o seguimento desta tônica por apenas uma átona, formando troqueu que pode ser executado em performance como espondeu. Dessa maneira, a possibilidade de variação no metro foi mantida, mas os dátilos foram mantidos fixos no quinto pé do hexâmetro e segundo hemistíquio do pentâmetro. A cesura obrigatória do pentâmetro datílico foi executada com a aproximação de duas tônicas e enfatizada com espaçamento obrigatório, que induz o leitor ao reinício do ritmo. Para manter o andamento do metro, foram utilizados recursos como deslocamento de tônica, elisão entre o fim do hexâmetro e início do pentâmetro, elisões em geral. A presente revisão apresenta alterações no hexâmetro, que procura executar as suas cesuras, porém com o resultado de várias cesuras femininas. Além disso, o tom do poema procurou maior leveza e fluidez, com a eliminação de hipérbatos radicais e o rearranjo de informações dentro do dístico, que é a unidade dentro do poema. O poema traduzido, oitavo do livro 1 , apresenta a figura da alcoviteira, personagem comum na comédia nova latina, que aqui é a presentada como uma bruxa que influencia a amada a extorquir os seus amantes e a desprezar o eu-poético, que sendo poeta, não tem como dar presentes valiosos além dos próprios poemas. Os efeitos estéticos utilizados incluíram aliterações e assonâncias, privilégio para repetições vocabulares e jogos de palavras que ocorrem no texto de partida, manutenção da posição enfática de palavras dentro dos versos, antíteses. Foi dada especial atenção aos jogos de palavras evidenciados pelo metro, como aqueles com contrastes ou paralelos entre os dois hemistíquios do pentâmetro. O resultado dessa tradução revisada é um poema mais fluido que a primeira versão, e que apresenta um maior domínio das possibilidades do metro. Os mesmos moldes dessa revisão estão sendo aplicados ao restante do livro 1, em revisão, e aos demais livros dos Amores.
\end{abstract}

Palavras-chave: Tradução poética. Experimentos de versificação. Ddístico elegíaco. Emulação do ritmo antigo. Elegia latina.

Abstract: This translation is part of a first review of a work presented in my Master's thesis (SOUZA, 2016). The proposal was to translate Ovid's elegiac couplets in a form that could echo the original rhythm of the Latin poem. To to that, I used Carlos Alberto Nunes' metrical choices as a reference, the substitution of long syllables in princeps position for stressed syllables in Portuguese. However, in my translation, different from Nunes, I admitted an stressed syllable to be followed by only one unstressed, compounding a trochee, which can be performatively executed as spondee. In this way, the possibility of variation was maintained in the meter, but the dactiles remained fixed as such in the hexameter's fifth foot and in the pentameter's second hemistich. The mandatory caesura in the pentameter was executed by having two stressed syllables side by side, and emphasized by a mandatory graphic space, in order to compel the reader to restart the rhythm. To maintain the pace of the meter, I employed resources as artificially displacing the stress to the beginning of a word, elision between a vowel-end of an hexameter and a vowel-beginning of the pentameter, and elisions in general. This revised version shows improvements in the hexameters, which now are preferentially executed with their caesuras, even with feminine caesuras as result. In addition, the tone of the poem is lighter and more fluid, with the elimination of radical hyperbata and the reorganization of content within the elegiac couplet, which is the unity in the poem. This translated poem, the eighth of book 1, presents the lena, a madam, a frequent character in the Latin new comedy, that here is portrayed as a witch who compels the beloved to extort her lovers and to despise the poetic voice, who, being a poet, cannot gift her anything more valuable than his own poems. This translation features aesthetic effects as alliterations and assonances, emphasis to word repetition and wordplays present in the Latin text, preservation of the emphatic 
position of words within the line, and antitheses. I privileged the wordplay emphasized by the meter, as in parallels and contrasts between the two hemistichs of the pentameter. The result of this reviewed translation is a poem more fluid than its first version, and which also presents a better command of the possibilities enabled by the meter. The same patterns of this work are being applied to my review of book 1 and to the remaining books of the Amores.

Keywords: Poetic translation. Experiments with meter. Elegiac couplet. Emulation of ancient rhythms. Latin elegy.

RECEBIDO EM: 18 de setembro de 2019

ACEITO EM: 25 de novembro 2019

PUBLICADO EM: março 2020 
$\mathrm{P}$ úblio Ovídio Nasão (43 a.C. - 18 d.C.) produziu poemas de diversos gêneros durante o principado de Augusto (31 a.C. - 14 d.C.), incluindo elegia amorosa e de exílio, épica, poemas em formato epistolar e tragédia. De família equestre, recebeu educação tradicional e circulou pelas mais importantes cenas literárias de Roma. Este poema é o oitavo do primeiro livro dos Amores, que foi a sua primeira produção, abarcando três livros, em dísticos elegíacos. Foi exilado para os confins do império por decreto de Augusto em 8 d.C. Ovídio especula em sua obra de exílio que seu manual de sedução, a Arte de amar, tenha pesado na sentença, além de questões pessoais que não são esclarecidas. Ovídio morreu sem jamais ter conseguido reverter sua sorte. Sua obra apresenta uma autoconsciência poética ligada aos efeitos do metro e do gênero (neste poema, o dístico elegíaco e a elegia amorosa), e também às suas referências e à sua posição na tradição literária. Além disso, frequentemente emprega elementos comuns em outros gêneros: o maior exemplo neste poema é a figura da alcoviteira, personagem frequente na comédia nova latina.

\section{Sobre o método de tradução}

A presente tradução do poema 1.8 dos Amores é a primeira revisão do trabalho iniciado em dissertação de mestrado (SOUZA, 2016). Em termos métricos, essa tradução apresenta a substituição das longas em posição princeps por tônicas, semelhante à proposta de Carlos Alberto Nunes para os épicos gregos e latino. Ao contrário da de Nunes, porém, essa tradução apresenta possibilidade de substituição de um dátilo por um troqueu (uma tônica e uma átona), o que em uma leitura em voz alta pode ser executado semelhante a um espondeu, alongando-se a átona em performance. Há o aproveitamento de tônicas secundárias em palavras longas. Os únicos pontos com substituição inadmissível foram a cláusula do hexâmetro (quinto pé sempre datílico) e o segundo hemistíquio do pentâmetro (que sempre apresenta andamento datílico). Há a presença de deslocamento da tônica inicial, especialmente nos pentâmetros, assim como elisão da átona inicial do pentâmetro com a átona final do hexâmetro, soluções que foram privilegiadas em relação à anacruse.

Apresenta-se um esquema do dístico elegíaco para referência. As cesuras do hexâmetro, cuja ocorrência pode ser no terceiro pé (pentemímera) ou no segundo (trimímera) e quarto (heptemímera) pés, não aparecem no esquema; a cesura obrigatória do pentâmetro está marcada: 


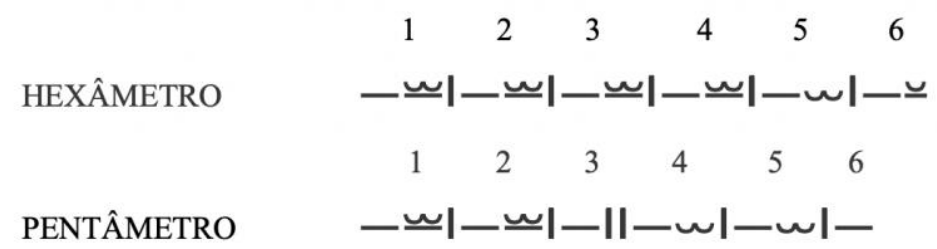

A cesura do pentâmetro, produzida preferencialmente pela aproximação de duas tônicas, foi indicada por meio de sinais de pontuação sempre que possível, além de um espaçamento obrigatório, que evidencia o reinício do ritmo e a estrutura em dois hemistíquios. A presente revisão da tradução inclui uma tentativa de trabalho com a cesura também nos hexâmetros, variando as ocorrências entre as posições possíveis no metro antigo. As cesuras do hexâmetro nessa tradução foram majoritariamente femininas.

O tom da tradução privilegiou uma escolha vocabular leve, com alguns coloquialismos, porém com alguns estranhamentos, normalmente por consequência do metro. Esta revisão privilegiou o tom mais leve e a fluidez do verso em relação à primeira versão no trabalho anterior, eliminando inversões sintáticas radicais e escolhas vocabulares e sintáticas que 132 dificultavam o entendimento do texto. Procurou-se destacar lugares comuns na poesia elegíaca, as repetições vocabulares e a posição chave de palavras dentro dos versos, assim como tensões provocadas por antíteses, especialmente entre os hemistíquios do pentâmetro.

Como efeitos estéticos, privilegiou-se a ocorrência de aliterações e assonâncias, além de tentativas de trabalhar os poliptotos, e a execução de diversas elisões. A unidade em termos de conteúdo foi o dístico elegíaco como um todo: embora a prioridade fosse trabalhar verso-averso, foi admitida uma reorganização do conteúdo, respeitando a integridade do dístico, de um verso a outro, o que auxiliou na construção de um texto mais fluido.

A versão utilizada para o texto de partida foi a estabelecida por E. J. Kenney (1994). 


\section{Ovídio, Amores 1.8}

Há uma certa (quem quer que queira saber de uma lena, ouça!), há certa mulher: Dipsa, se chama a anciã.

Tal nome vem do seguinte: jamais à madre do negro

Mêmnon, em róseo corcel, sóbria ela pôde encarar.

Ela conhece as mágicas artes, feitiços de Ea;

dizem que pode dobrar rio à nascente outra vez.

Sabe bem o que valem as ervas e fios de fusos tortos, e qual poção de égua no cio é melhor.

Quando quer, em todo o orbe, se englobam as nuvens, quando quer, brilharão puros os dias no céu.

Sangue, se crês em mim, gotejava, eu vi, das estrelas, púrpura era o luar, era sangrenta expressão.

Que ela mude de forma e voe nas sombras da noite eu suspeito, também, cheia de penas, senil.

Eu suspeito, é a fama. Pupilas dos olhos, e duplas, brilham e gêmeo olhar vem como raios luzir.

Ela evoca os avós e tataravós dos sepulcros, fende o sólido chão com um extenso encantar.

Ela propôs para si profanar os leitos pudicos; língua maldita, jamais perde a sua persuasão.

Testemunhei um discurso, ao acaso, e ela instruía coisas assim (me escondi indo por trás do portão):

"Sabes, minha luz, o quanto agradaste um rico garoto? junto contigo ficou, fixos os olhos em ti.

E por que não iria? Tuas formas, ninguém ultrapassa; ai!, que falta te faz digno do corpo o polir.

Quero que sejas feliz, assim como és bem formosa.

Pobre eu não serei, se eu te fizer enricar.

Astros com Marte contrário que foram a ti prejuízo;

Marte se foi, mas vem Vênus com aptos sinais.

Útil que venha, olha só: um amante ricaço cobiça 
a ti: e ele cuida e provê tudo que venha a faltar.

Esse rapaz tem ainda um rosto que ao teu se compara: se te comprar não quiser, compra tu mesma o rapaz.

Enrubesceu: adorno é o pudor na alva face, mas esse, se é fingido, cai bem; vai estorvar se real.

Quando lançares de acordo teus olhos baixados ao colo, tanto quanto trouxer, vai teu respeito ganhar.

Ah, talvez com Tácio reinante as impuras Sabinas não quisessem casar, sendo de mais de um varão.

Marte agora excita o ânimo a guerras externas, Vênus reina, porém, com seu Eneias aqui.

Brincam as belas; casta, somente com quem ninguém flerta; ou, se rudez não impedir, vai ela mesma flertar.

Há mesmo aquelas que trazem as rugas no meio da testa: agita essas rugas que então múltiplos crimes decaem.

134 Vimos que as forças dos jovens, Penélope no arco tentava: arco de chifres provou força e do flanco o vigor.

Corre escondido e a nós engana o tempo volátil, como torrente veloz corre nas águas e vai.

Bronzes brilham com uso, e as boas vestes se entrajam; casa largada estará velha com torpe bolor.

Formas, se não receberes, decaem sem ter exercício; não é bastante, porém, só um e outro manter:

Certo de muitos tirar, nem tão invejosa rapina; farta presa da grei vem para o lobo ancião.

Eis, que pode o teu vate, além de novos poemas, dar-te? Pois muitos mil dos teus amantes lerás.

Mesmo o deus dos vates, visível com pálio de ouro, toca na lira uns sons, pelos dourados cordões.

Dando, que seja a ti maior que o magnífico Homero; crê no que digo, pois dar é uma questão genial.

Nem se alguém for comprado com o preço da própria cabeça, não o desprezes, é vão o crime de ter pés de giz. 
Nem te enganem os velhos de cera ao redor da antessala:

leva contigo os avós, ó miserável galã!

Há alguém, porque belo, que queira uma noite de graça?

Antes que ele te dê o que ele exige do amor!

Pede um preço mais parco, enquanto estendes a rede, pra ele não te deixar; preso, que queime à tua lei.

Falso amor não machuca, permite a ele crer ser amado; cuida pra não te sair grátis assim esse amor.

Nega várias noites, e ora uma dor de cabeça, ora a Ísis servir possa desculpas te dar.

Logo lhe abra a porta, que assim não fica sofrendo, nem poderá afrouxar, se repelires o amor.

Surda se faça a tua porta aos que pedem, mas frouxa aos que trazem, deixa o acolhido ouvir gritos que vêm do portão; como se antes ferida, discute com quem tu feriste, pois tua culpa se esvai, se outro tiver culpa igual.

Mas que tu nunca dês um tempo espaçoso pra iras: ira retida demais várias rixas já fez.

Que também os teus olhos aprendam o choro forçado: ou um e outro chorar umedecendo a expressão.

Se a alguém enganares, não temas fazer o perjúrio:

Vênus os numes deixou surdos aos jogos de amor.

Para cumprir o papel, prepara escravos audazes, mostrem a ele quais são coisas que possa comprar.

Peçam pouco pra si, pois pouco pedindo de muitos, dessas migalhas terão grandes recursos enfim.

Tanto tua irmã, como a mãe e a nutriz, que arranquem do amante:

sob o ataque das mãos rápido a presa já cai.

Quando faltar-te razão pra poder pedir mais presentes, mostra com bolo ao rapaz: teu natalício chegou!

Cuida que ele não ame seguro sem ter concorrente: sem batalhar um rival, não durará esse amor.

Este que veja em todo o leito vestígios dos outros, 
lívida note a cerviz, cheia de marcas carnais.

O principal, ele ver os presentes mandados por outro.

Se não ganhar de ninguém, vai para a rua pedir.

Quando tomares aos montes, e pra que nem tudo te doe, algo pra não devolver pede emprestado pra ti!

Língua ajude e proteja a mente, mordendo e assoprando: cobrem-se ímpias poções sob o mais doce do mel.

Se meu conselho ouvires, que pude aprender com o tempo,

vento ou brisa não for longe levar minha voz;

sempre então farás orações pela minha saúde

que os meus ossos enfim deitem finados em paz - "

Ia em curso a voz, porém me traíram as sombras.

Ah, que esforço que foi, pra eu conter minhas mãos!

Esses cabelos, brancos e raros, o olhar lacrimoso

de álcool e a face senil, quase que eu lhe rasguei.

136 Deuses te tomem os Lares, que deem velhice indigente, sede perpétua também, longos invernos, por fim!

\section{Sobre a tradutora}

Luiza dos Santos Souza formou-se em Letras (português e latim) pela Universidade Federal do Paraná (UFPR) e obteve o título de mestre em Letras, com ênfase em estudos literários, pela mesma instituição. Sua pesquisa envolveu crítica e prática de tradução, e história da tradução dos clássicos greco-latinos no Brasil. Iniciou no mestrado um projeto de tradução dos Amores de Ovídio que procura ecoar por meio das escolhas métricas o ritmo do dístico elegíaco latino. Atualmente, revisa o livro primeiro, que terminou no mestrado, e expande o projeto para os outros dois livros. Desenvolve sua tradução em paralelo ao doutorado em Estudos Clássicos na University of Cincinnati (Ohio - EUA).

\section{BIBLIOGRAFIA SELECIONADA}

HOMERO; NUNES, C. A. (trad.) Ilíada. Rio de Janeiro: Ediouro, 1989.

HOMERO; NUNES, C. A. (trad.) Odisseia. Rio de Janeiro: Ediouro, 2002.

McKEOWN, J. C. Ovid: Amores. Text, prolegomena and commentary in four volumes. v.2. Great Britain: Francis Cairns (Publications), 1989. 
OVÍDiO; KENNEY, E. J. (ed.) Amores, Medicamina Faciei Femineae, Ars Amatoria, Remedia Amoris. 2nd. ed. Oxford: Oxford University Press, 1994.

OVÍDIO; SHOWERMAN, G. (ed.) Heroides: Amores. 2nd. ed. Cambridge, Mass.; London: Harvard University Press, 1977.

SOUZA, L. dos S. Bi-tradução do livro primeiro dos Amores de Ovídio: reflexões sobre dois modos de verter o dístico elegíaco. Dissertação (Mestrado em Letras) - Setor de Ciências Humanas, Universidade Federal do Paraná. Curitiba, 2016.

VIRGÍliO; NUNES, C. A. (trad.); OLIVA NETO, J. A. (org.) Eneida. São Paulo: Ed. 34, 2014.

WEST, M. Studies in Greek Elegy and Iambus. Berlin: De Gruyter, 1974.

WEST, M. Greek Metre. New York: Oxford, 1996.

\footnotetext{
* Luiza dos Santos SOUZA - Graduada em Letras - Latim (2013) pela Universidade Federal do Paraná. Mestre em Letras (2016) pela mesma instituição. Doutoranda em Classics pela University of Cincinnati, EUA. University of Cincinnati, College of Arts and Sciences, Department of Classics. Cincinnati, Ohio. Estados Unidos da América. Currículo acadêmico: http://lattes.cnpq.br/5395027268440645

ORCID: https://orcid.org/0000-0002-7716-6194

E-mail: luizasouza1040@hotmail.com
} 